\title{
Effect of lignocaine on conducting system of human heart
}

\author{
S. Bekheit, ${ }^{1}$ J. G. Murtagh, P. Morton, and E. Fletcher \\ From the Cardiovascular Unit, Belfast City Hospital, Northern Ireland
}

The effects of lignocaine on atrioventricular conduction, particularly in relation to pre-existing disease of the specialized conducting tissues, were studied. Ten patients, 7 of whom had symptomatic coronary heart disease, were selected, and 4 had first-degree His-Purkinje system (HPS) block (HV interval > 55 msec). His bundle electrograms were recorded in each patient: (I) under basic resting conditions (basic tracings), (2) during stressing of the conducting system by atrial pacing at rates from 80 to 150 beats per minute (control tracings), (3) as in (2), but after the administration of $100 \mathrm{mg}$ lignocaine intravenously (lignocaine tracings). The PA interval, representing intra-atrial conduction time, $A H$ interval, representing $A V$ nodal conduction time, $H V$ interval, representing conduction time in the His-Purkinje system, and HS interval, representing total intraventricular conduction time, were measured for analysis of the basic tracings, and for comparison of the effects of lignocaine on the series of paced heart rates.

Lignocaine had a variable effect on $A V$ conduction when the conducting tissues were stressed by atrial pacing. The changes due to lignocaine were confined almost exclusively to the $A V$ node with no effect on intraatrial or His-Purkinje system conduction and only minimal effect on intraventricular conduction. It was found that the AH interval after the administration of lignocaine was shortened at certain paced rates, and in other patients it was lengthened, compared with the control tracings at the same paced rates. The differences were not significant either for the group as a whole or for the $A H$ values at each paced rate. $A$ possible explanation of the variable effect of lignocaine on $A V$ nodal conduction is discussed.

It is concluded that therapeutic doses of lignocaine have no significant effect on the specialized conducting tissues even in the presence of disease of the His-Purkinje system.

Lignocaine is an effective drug in the suppression of abnormal ventricular beats (Grossman et al., 1967; Spracklen et al., I968). It is now the universally accepted agent of choice for management of ventricular ectopic activity in the early phase of acute myocardial infarction (Lown and Vassaux, 1968; Jewitt, Kishon, and Thomas, 1968). It has been shown that lignocaine in therapeutic doses has insignificant haemodynamic effects (Binnion et al., 1969). However, Lieberman et al. (1968) found that it depressed cardiac conduction when given to dogs in high dosage, but few studies of the effect of lignocaine on conduction in the human heart have been reported (Rosen et al., 1970). The purpose of this paper is to provide information about the effects of lignocaine on the specialized conducting fibres and, in particular, since atrioventricular conduction may

Received 3I July 1972.

${ }^{1}$ Research Fellow, Northern Ireland Hospitals Authority. be impaired or blocked in myocardial infarction, to ascertain if the drug contributes to heart block, especially when the conducting tissues are diseased.

\section{Methods}

Ten patients were studied, 7 men aged between 45 and 70 years, and 3 women aged 50 to 52 years. The procedures to be adopted and the purpose of the study was explained to each patient and consent obtained. A His bundle electrogram was recorded by the method described by Scherlag et al. (1969) in which the rapid deflection of depolarization of the bundle of $\mathrm{His}$ is picked up by an electrode catheter placed alongside the main bundle as it lies in the right ventricle adjacent to the tricuspid valve. The technique employed has been described in detail by us previously (Bekheit et al., 1971), and it will be summarized only briefly here. A bipolar electrode catheter was introduced into the femoral vein percutaneously and its tip advanced under fluoroscopic control to the inflow tract of the right ventricle. The catheter was attached to an AC input 
TABLE I Clinical data and basic His bundle electrogram measurements

\begin{tabular}{|c|c|c|c|c|c|c|c|c|}
\hline \multirow[t]{2}{*}{$\begin{array}{l}\text { No. of } \\
\text { patients }\end{array}$} & \multirow[t]{2}{*}{$\begin{array}{l}\text { Age } \\
(y r)\end{array}$} & \multirow[t]{2}{*}{ Sex } & \multirow[t]{2}{*}{$\begin{array}{l}\text { Weight } \\
(\mathrm{kg})\end{array}$} & \multirow[t]{2}{*}{ Disease } & \multicolumn{4}{|c|}{$\begin{array}{l}\text { Basic His bundle } \\
\text { electrogram (msec) }\end{array}$} \\
\hline & & & & & $P A$ & $A H$ & $H V$ & $H S$ \\
\hline $\mathbf{I}$ & 62 & Male & 70 & Coronary heart disease & 30 & 80 & 50 & 120 \\
\hline 2 & 50 & Female & 83 & Normal heart & I0 & 90 & 40 & 120 \\
\hline 3 & 61 & Male & 67 & Coronary heart disease & 15 & 105 & 50 & 120 \\
\hline 4 & 52 & Female & 65 & Coronary heart disease & 20 & 85 & 65 & 120 \\
\hline 5 & 65 & Male & 58 & Coronary heart disease & 30 & 65 & 55 & 125 \\
\hline 6 & 68 & Male & 69 & Calcific aortic stenosis & 25 & 95 & 60 & 130 \\
\hline 7 & 45 & Male & 78 & Recent myocardial infarction & 30 & Iro & 60 & 100 \\
\hline 8 & 70 & Male & 73 & Recent myocardial infarction & 15 & 115 & 80 & 170 \\
\hline 9 & 52 & Male & 73 & Starr Edwards aortic valve & 35 & 80 & 40 & 200 \\
\hline I0 & 50 & Female & 58 & Coronary heart disease & 25 & 120 & 45 & I IO \\
\hline
\end{tabular}

PA, internodal atrial conduction time; $\mathrm{AH}, \mathrm{AV}$ nodal conduction time; HV, His-Purkinje system conduction time; HS, total intraventricular conduction time.

preamplifier (Sanborn No. 350-2700) with a frequency response 15-1500 cycles a second, and manipulated until a rapid deflection ( $\mathrm{H}$ wave) appeared in each beat on the oscilloscope. The His bundle electrogram was then photographed with a standard limb lead at a paper speed of $100 \mathrm{~mm}$ per second. The tracing obtained in this way is referred to as the 'basic tracing' in the analysis of results. A second electrode catheter was then introduced through a right arm vein and attached to an external pacemaker (Medtronic 5880A). The tip of the catheter was advanced to a pacing position against the wall of the right atrium. The atrium was paced to override the sinus node at rates from 80 to 150 beats a minute. If Wenckebach block occurred no further in-

TABLE 2 His bundle electrogram measurements before and after lignocaine

\begin{tabular}{|c|c|c|c|c|c|c|c|c|c|c|c|c|c|c|c|c|c|}
\hline \multirow{4}{*}{$\begin{array}{l}\text { Case } \\
\text { No. }\end{array}$} & & \multicolumn{16}{|c|}{ Pacing rate per minute } \\
\hline & & \multicolumn{4}{|l|}{80} & \multicolumn{4}{|l|}{90} & \multicolumn{4}{|l|}{100} & \multicolumn{4}{|l|}{ IIO } \\
\hline & & $P_{1} A$ & $A H$ & $H V$ & $H S$ & $P_{1} A$ & $A H$ & $H V$ & $H S$ & $P_{1} A$ & $A H$ & $H V$ & $H S$ & $P_{1} A$ & $A H$ & $H V$ & $H S$ \\
\hline & & (msec) & & & & (msec) & & & & (msec) & & & & $(m s e c)$ & & & \\
\hline \multirow[t]{2}{*}{ I } & C & & & & & & & & & & & & & 50 & 95 & 50 & 120 \\
\hline & L & & & & & & & & & & & & & 50 & 95 & 50 & 120 \\
\hline \multirow[t]{2}{*}{2} & C & & & & & & & & & 80 & 90 & 40 & 120 & & & & \\
\hline & L & & & & & & & & & 80 & 100 & 40 & 120 & & & & \\
\hline \multirow[t]{2}{*}{3} & C & & & & & & & & & 60 & 140 & 40 & II5 & 60 & 160 & 40 & 115 \\
\hline & $\mathrm{L}$ & & & & & & & & & 60 & 140 & 40 & 115 & 60 & 160 & 40 & II5 \\
\hline \multirow[t]{2}{*}{4} & $\mathrm{C}$ & & & & & & & & & 45 & 90 & 65 & 120 & 45 & 120 & 65 & 120 \\
\hline & L & & & & & & & & & 45 & 90 & 65 & 120 & 45 & 120 & 65 & 120 \\
\hline \multirow[t]{2}{*}{5} & C & & & & & 55 & 75 & 50 & 125 & 55 & 80 & 50 & 125 & 55 & 80 & 50 & 125 \\
\hline & L & & & & & 55 & 75 & 50 & 125 & 55 & 80 & 50 & 125 & 55 & 90 & 50 & 125 \\
\hline \multirow[t]{2}{*}{6} & C & 45 & 120 & 60 & 155 & 45 & 130 & 60 & 160 & 45 & 150 & 60 & 160 & 45 & 170 & 60 & 160 \\
\hline & L & 40 & 140 & 60 & 160 & $\begin{array}{l}45 \\
45\end{array}$ & 150 & 60 & 160 & $\begin{array}{l}45 \\
45\end{array}$ & 155 & 60 & 160 & $\begin{array}{l}43 \\
45\end{array}$ & 160 & 60 & 160 \\
\hline \multirow[t]{2}{*}{7} & $\overline{\mathrm{C}}$ & & & & & & & & & 50 & 120 & 60 & 100 & 50 & 140 & 60 & 100 \\
\hline & L & & & & & & & & & 50 & 120 & 60 & 100 & 50 & 140 & 60 & 100 \\
\hline \multirow[t]{2}{*}{8} & C & & & & & & & & & 30 & 290 & 80 & 150 & & & & \\
\hline & L & & & & & & & & & 30 & 165 & 80 & 150 & & & & \\
\hline \multirow[t]{2}{*}{9} & C & & & & & & & & & & & & & 70 & 90 & 40 & 200 \\
\hline & L & & & & & & & & & & & & & 70 & 100 & 40 & 200 \\
\hline \multirow[t]{2}{*}{10} & C & & & & & 40 & 145 & 45 & I 10 & 40 & 155 & 45 & IIO & 40 & I 75 & 45 & IIO \\
\hline & & & & & & 40 & 145 & 45 & I10 & 40 & 165 & 45 & IIO & 40 & 180 & 45 & I 10 \\
\hline $\begin{array}{l}t \text { test for } \\
\text { pooled } A-H \\
\text { values }\end{array}$ & & - & & & & $0.20=$ & $P>0$. & & & $0.20>$ & $\mathbf{P}>0$. & & & $0.40=$ & $P>0$ & & \\
\hline
\end{tabular}

$\mathrm{P}_{1} \mathrm{~A}$, inter-atrial conduction time; $\mathrm{AH}, \mathrm{AV}$ nodal conduction time; HV, His-Purkinje system conduction time; HS, total intraventricular conduction time; $C$, control measurements; $L$, measurements after lignocaine. 
crease in the paced rate was employed. The His bundle electrogram together with a standard surface lead was recorded at each paced rate. The procedure was then repeated to confirm the constancy of the increments of conduction for each selected paced rate. The His bundle electrograms obtained by this method represent the 'control tracings'. Lignocaine in a dose of $100 \mathrm{mg}$ was then administered intravenously over a period of one minute and the pacing procedure repeated in duplicate at identical rates as in the controls, within a ro-minute interval from the administration of lignocaine. These tracings are referred to in the analysis of results as 'lignocaine tracings'. As in the controls, the measurements of the two sets of lignocaine tracings were identical, thus confirming the stability of the system. The dose of lignocaine used in this study (100 $\mathrm{mg}$ i.v.) can be assumed to maintain therapeutic plasma concentrations (I-4 $\mu \mathrm{g} / \mathrm{l}$.) for the weight range of the patients (57.6$83.4 \mathrm{~kg}$ ) (Binnion et al., 1969). The lignocaine paced recordings were completed well within the half-life of the drug in the body (Sung and Truant, 1954; Hayes et al., 1967). The following increments of conduction were measured for analysis of the basic tracings and for comparison of the effects of lignocaine on the series of paced heart rates. (I) PA interval, representing intra-atrial conduction time, from the sinus $P$ wave in the basic tracings or the spike of the artificial impulse $(\mathrm{PI})$ in the control and lignocaine tracings to the $A$ wave recorded by the $\mathrm{His}$ bundle electrode atrial fibres immediately adjacent to the AV node. (2) AH interval, representing atrioventricular (AV) nodal conduction time. (3) HV interval representing conduction time in the His-Purkinje system (HPS). (4) HS interval representing total intraventricular conduction time. The normal values of these intervals are shown in Table I (Bekheit et al., I97I).

\section{Results}

Table I summarizes the clinical details of the patients and shows the measurements of conduction in the basic tracings. Seven of the patients had coronary heart disease including 2 with recent myocardial infarction (Cases $1,3,4,5,7,8$, 10). Case 2 had a normal heart, Case 6 calcific aortic stenosis, and Case 9 a Starr-Edwards aortic valve prosthesis. Cases 6 and 7 were on maintenance digoxin $0.25 \mathrm{mg}$ twice daily, at the time when the His bundle electrogram was recorded.

The measurements of the increments of conduction for the 'control' and 'lignocaine' tracings, at serial paced rates from 80 to I 50 beats a minute are shown in Table 2. Each interval was constant at each paced rate over not less than 20 cycles.

\begin{tabular}{|c|c|c|c|c|c|c|c|c|c|c|c|c|c|c|c|c|}
\hline \multicolumn{4}{|l|}{120} & \multicolumn{4}{|l|}{130} & \multicolumn{4}{|l|}{140} & \multicolumn{4}{|l|}{150} & \multirow{3}{*}{$\begin{array}{l}\text { Pooled } A H \\
(m s e c)\end{array}$} \\
\hline$P_{1} A$ & $A H$ & $H V$ & $H S$ & $P_{1} A$ & $A H$ & $H V$ & $H S$ & $P_{1} A$ & $A H$ & $H V$ & $H S$ & $P_{1} A$ & $A H$ & $H V$ & $H S$ & \\
\hline \multirow{3}{*}{\multicolumn{2}{|c|}{ (msec) }} & & & \multicolumn{4}{|l|}{ (msec) } & \multicolumn{4}{|c|}{ (msec) } & \multicolumn{4}{|c|}{ (msec) } & \\
\hline & & & & 50 & 100 & 50 & 120 & 50 & 130 & 50 & 125 & 50 & 135 & 50 & 120 & 460 \\
\hline & & & & 50 & 100 & 50 & 120 & 50 & 105 & 50 & 125 & 50 & 140 & 50 & 120 & 440 \\
\hline 80 & 120 & 40 & 120 & & & & & 80 & 120 & 40 & 120 & & & & & 330 \\
\hline 80 & 120 & 40 & 120 & & & & & 80 & 120 & 40 & 120 & & & & & 340 \\
\hline 60 & 170 & 40 & 115 & 60 & 180 & 40 & 115 & & & & & 60 & 190 & 40 & II5 & 840 \\
\hline 60 & 170 & 40 & 115 & 60 & 180 & 40 & 115 & & & & & 60 & 190 & 40 & 115 & 840 \\
\hline 45 & 120 & 65 & 120 & 45 & 120 & 65 & 120 & & & & & 45 & 120 & 65 & 120 & 570 \\
\hline 45 & 120 & 65 & 120 & 45 & 120 & 65 & 120 & & & & & 45 & 120 & 65 & 120 & 570 \\
\hline 55 & 95 & 50 & 125 & 55 & 100 & 50 & 120 & 55 & 105 & 50 & 120 & 55 & IIO & 50 & 120 & 645 \\
\hline 55 & 95 & 50 & 125 & 55 & 100 & 50 & 120 & 55 & 105 & 50 & 120 & 55 & IIO & 50 & 120 & 655 \\
\hline 45 & 180 & 60 & 160 & 45 & 190 & 60 & 160 & & & & & $\mathbb{W}$ & & & & 945 \\
\hline 45 & 200 & 60 & 160 & 45 & 245 & 60 & 160 & & & & & & & & & 1040 \\
\hline 50 & 160 & 60 & 100 & 50 & 180 & 60 & 100 & 50 & 190 & 60 & 100 & 50 & 195 & 60 & 100 & 985 \\
\hline 50 & 160 & 60 & 100 & 50 & 160 & 60 & 100 & 50 & 190 & 60 & 100 & 50 & 195 & 60 & 100 & 965 \\
\hline \multirow[t]{2}{*}{ W } & & & & & & & & & & & & & & & & 295 \\
\hline & & & & & & & & & & & & & & & & 170 \\
\hline 70 & 100 & 40 & 200 & 70 & I 10 & 40 & 200 & 70 & 120 & 40 & 200 & 70 & 125 & 40 & 200 & 545 \\
\hline 70 & IIO & 40 & 200 & 70 & IIO & 40 & 200 & 70 & 120 & 40 & 200 & 70 & 125 & 40 & 200 & 565 \\
\hline 40 & 180 & 45 & IIO & 40 & 200 & 45 & IIO & W & & & & & & & & 855 \\
\hline 40 & 180 & 45 & I IO & 40 & 160 & 45 & I 10 & & & & & & & & & 830 \\
\hline \multicolumn{4}{|c|}{$0.5>P>0.10$} & \multicolumn{4}{|c|}{$0.35>P>0.4$} & \multicolumn{4}{|c|}{$0.15>P>0.20$} & \multicolumn{4}{|c|}{$0.15>P>0.20$} & $0.30>P>0.35$ \\
\hline
\end{tabular}




\section{Intra-atrial conduction}

In the 47 instances of paced rate in the ro patients the $P_{1} A$ interval in the lignocaine tracings was identical with the control tracings. Lignocaine therefore had no effect on the velocity of atrial conduction between the site of the artificial impulse and the AV node. Further, atrial conduction was not altered by change in the paced rate but the $P_{1} A$ interval at the paced rates exceeded the PA intervals of the basic tracings (Table I). The explanation appears to de- pend on the nonhomogeneous conduction of atrial muscle. Sinus impulses reach the AV node rapidly through preferential pathways (James and Sherf, 197I). When the atrium is artificially paced, on the other hand, impulses may fail to travel preferentially at least by the shortest routes to the AV node, thereby resulting in prolongation of the $P_{1} A$ interval. Prolonged intra-atrial conduction is therefore a function of pacing and it is not influenced by lignocaine.
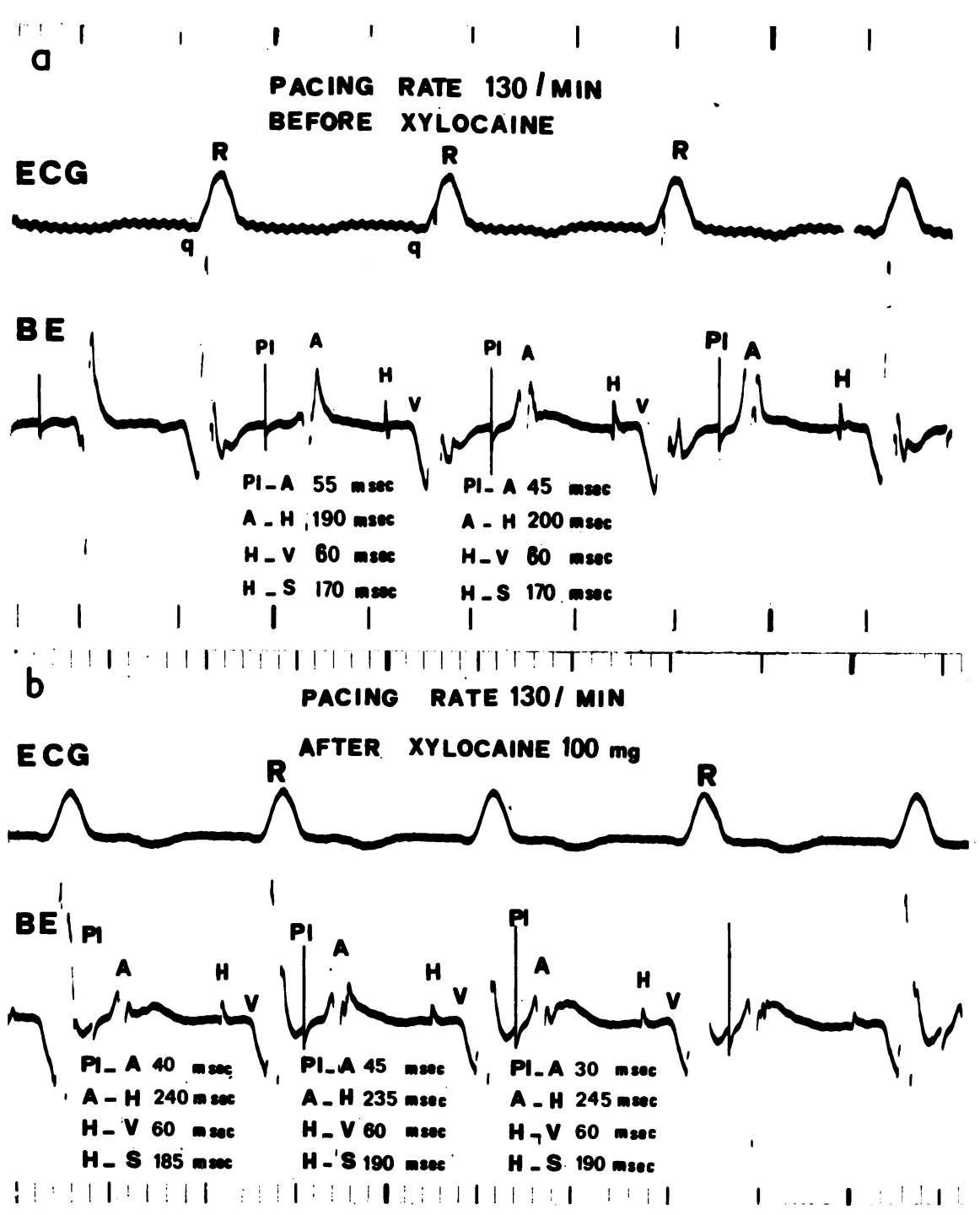

FIG. I The effect of lignocaine on $A V$ nodal conduction $(A H)$ interval in Case 8. Note the shortening of the $A H$ ) interval from 290 msec before lignocaine to $165 \mathrm{msec}$ after lignocaine (cf. Fig. 2). (Distance between 2 light divisions equals $40 \mathrm{msec}$.) 


\section{AV nodal conduction}

Wenckebach block occurred in Cases 6, 8, and ro, at paced rates 150, 110, and 140, respectively, both in the control and in the lignocaine tracings. There was no evidence therefore that lignocaine was responsible for complete block of impulses in the AV node. However, lignocaine had a variable effect on the AH interval, e.g. in Case 8, at a paced rate of Ioo beats a minute the $\mathrm{AH}$ interval was shortened from $290 \mathrm{msec}$ in the control to $165 \mathrm{msec}$ after lignocaine, whereas in Case 6, at a paced rate of 130 beats a minute the $\mathrm{AH}$ interval was prolonged from $190 \mathrm{msec}$ in the control to $245 \mathrm{msec}$ after lignocaine. These paradoxical effects on the AH interval are illustrated in Fig. I and 2. In order to determine the significance of the variation in the $\mathrm{AH}$ intervals after lignocaine the serial $\mathrm{AH}$ values for each patient were summated (pooled numbers Table 2). The difference in pooled numbers of the control and lignocaine tracings varied from $(+95)$ to $(-125)$ msec, but for the group as a whole the difference between them was not significant $(P=0.35)$. The $\mathrm{AH}$ values at each paced rate in the group were then compared and in no instance was the difference significant $(P=0.20$ at rates 140,150 a minute to $\mathbf{P}=0.45$ at $\mathbf{I}$ Io beats a minute Table 2 ). Lignocaine had no significant effect on AV conduction for the group as a whole at the paced rates studied. Fig. 3 illustrates the slight range of variation of $\mathrm{AH}$ intervals expressed as a summation of $\mathrm{AH}$ values at various paced heart rates.

\section{His-Purkinje system conduction}

The HV interval remained fixed at all paced rates

FIG. 2 The effect of lignocaine on $A V$ nodal conduction $(A H)$ interval in Case 6. Note the lengthening of the $(A H)$ interval from 190 msec before lignocaine to $240 \mathrm{msec}$ after lignocaine (cf. Fig. I). (Distance between 2 light divisions equals $40 \mathrm{msec}$.) 




FI G. 3 The histogram shows the slight range of variation of the pooled values for $A V$ nodal conduction $(A H)$ intervals at paced heart rates ranging between 90 to I 50 beats a minute. The number of cases studied at each paced rate is shown between brackets above the columns.

in each patient and its measurements in the control and lignocaine tracings were identical and these in turn were identical with the HV intervals of the basic tracings (Table I). Lignocaine therefore did not affect the velocity of conduction from the time of initial depolarization of the main bundle of His to the arrival of the impulse at the Purkinje myocardial function either in patients with normal HisPurkinje system conduction in whom the HV interval was initially prolonged ( $\mathrm{HV}>55 \mathrm{msec}$ in Cases $4,6,7$, and 8 ).

\section{Intraventricular conduction}

The HS interval was constant at all paced rates in the control and lignocaine tracings. In some cycles, however, it was either slightly longer or shorter after lignocaine (Fig. I and 2). It was concluded nevertheless that lignocaine had no significant effect on intraventricular conduction.

\section{Discussion}

Of the ro patients in this study, 9 had organic heart disease; 7 had symptomatic coronary heart disease; 2 of whom were studied within two weeks from the onset of acute myocardial infarction; 2 patients had advanced aortic valve disease. It should be noted that first-degree His-Purkinje system block was associated with coronary heart disease in 4 patients. The results of our observations confirm that lignocaine has a variable effect on atrioventricular conduction when the specialized conducting tissues are stressed by atrial pacing. Moreover, changes due to lignocaine are confined almost exclusively to the AV node, with minimal effect on intraventricular conduction, and no effect on intra-atrial or HPS conduction, even in the presence of disease of the HisPurkinje system. In no instance was the sinus conduction completely blocked at any site. The effect on the AV node requires particular comment. The reciprocal innervation of the sinus and AV nodes by autonomic nerve endings ensures that the increased rate of discharge of the former is accompanied by increased velocity of conduction in the latter, e.g. the release of vagal tone in the normal heart after exercise. The autonomic response of both nodes may therefore be said to be 'in phase'. Artificial atrial impulses, on the other hand, are independent of autonomic nerve impulses and increasing paced rates reveal decremental conduction as an intrinsic property of AV nodal tissue. Nevertheless, reciprocal innervation of the $A V$ node remains intact during atrial pacing and the slight variation in AV nodal conduction obtained with lignocaine may reflect changes in vagal tone rather than a direct action of the drug on the fibres of the AV node.

The clinical implications of the effects of lignocaine on AV conduction are important. Our results are similar to those of Rosen et al. (1970) who showed that therapeutic doses of the drug had no significant effect on AV conduction. Atrioventricular block may occur in the acute phase of myocardial infarction, and it is not clear in the two cases of Gianelly et al. (1967) whether the heart block occurred in the natural history of infarction or whether it was related to the administration of lignocaine. In contradistinction to the findings of Nagle and Pilcher (I968) ectopic ventricular rhythms did not occur in any of the 47 paced rates in our series. We suggest, therefore, that lignocaine can be administered with confidence in acute myocardial infarction to suppress ventricular ectopic activity without producing any significant effect on myocardial conduction, and if heart block occurs it is likely to be part of the natural history of infarction and not related to lignocaine in therapeutic doses. Further, when a temporary pacemaker is inserted for the management of heart block, lignocaine can continue to be used to suppress undesirable ventricular arrhythmias without likelihood that the drug will maintain heart block or delay the spontaneous restoration of normal conduction.

\section{References}

Bekheit, S., Murtagh, J. G., Morton, P., and Fletcher, E. (197I). Measurements of sinus impulse conduction from electrogram of bundle of His. British Heart fournal, 33, 719. 
Binnion, P. F., Murtagh, G., Pollock, A. M., and Fletcher, E. (1969). Relation between plasma lignocaine levels and induced haemodynamic changes. British Medical fournal, 3, 390.

Gianelly, R., Von Der Groeben, J. O., Spivack, A. P., and Harrison, D. C. (1967). Effect of lidocaine on ventricular arrhythmias in patients with coronary heart disease. New England fournal of Medicine, 277, 1215.

Grossman, J. I., Lubow, L. A., Frieden, J., and Rubin, I. L. (1967). Lidocaine in cardiac arrhythmias. Circulation, 35 and 36, Suppl. II, 126.

Hayes, J. G., Ettinger, E., Wanat, F. E., and Killip, T. (I967). Evaluation of lidocaine in the treatment of ventricular arrhythmia. Circulation, 35 and 36, Suppl. II, 137.

James, T. N., and Sherf, L. (197I). Specialized tissues and preferential conduction in the atria of the heart. American Fournal of Cardiology, 28, 414.

Jewitt, D. E., Kishon, Y., and Thomas, M. (1968). Lignocaine in the management of arrhythmias after acute myocardial infarction. Lancet, $\mathbf{1}, 266$.

Lieberman, N. A., Harris, R. S., Katz, R. I., Lipschutz, H. M., Dolgin, M., and Fisher, V. J. (I968). The effect of lidocaine on the electrical and mechanical activity of the heart. American fournal of Cardiology, 22, 375.
Lown, B., and Vassaux, C. (1968). Lidocaine in acute myocardial infarction. American Heart fournal, 76, 586.

Nagle, R. E., and Pilcher, J. (1968). Lignocaine for arrhythmias. Lancet, $\mathbf{r}, 1039$.

Rosen, K. M., Lau, S. H., Weiss, M. B., and Damato, A. N. (1970). The effect of lidocaine on atrioventricular and intraventricular conduction in man. American fournal of Cardiology, 25, I.

Scherlag, B. J., Lau, S. H., Helfant, R. H., Berkowitz, W. D., Stein, E., and Damato, A. N. (1969). Catheter technique for recording His bundle activity in man. Circulation, 39, 13.

Spracklen, F. H. N., Kimerling, J. J., Besterman, E. M. M., and Litchfield, J. W. (1968). Use of lignocaine in treatment of cardiac arrhythmias. British Medical fournal, I, 89.

Sung, C. Y., and Truant, A. P. (1954). The physiological disposition of lidocaine and its comparison in some respects with procaine. Fournal of Pharmacology and Experimental Therapeutics, 112, 432.

Requests for reprints to Dr. Evan Fletcher, Belfast City Hospital, Belfast $\mathrm{BT}_{9}{ }_{7 \mathrm{AB}}$, Northern Ireland. 